
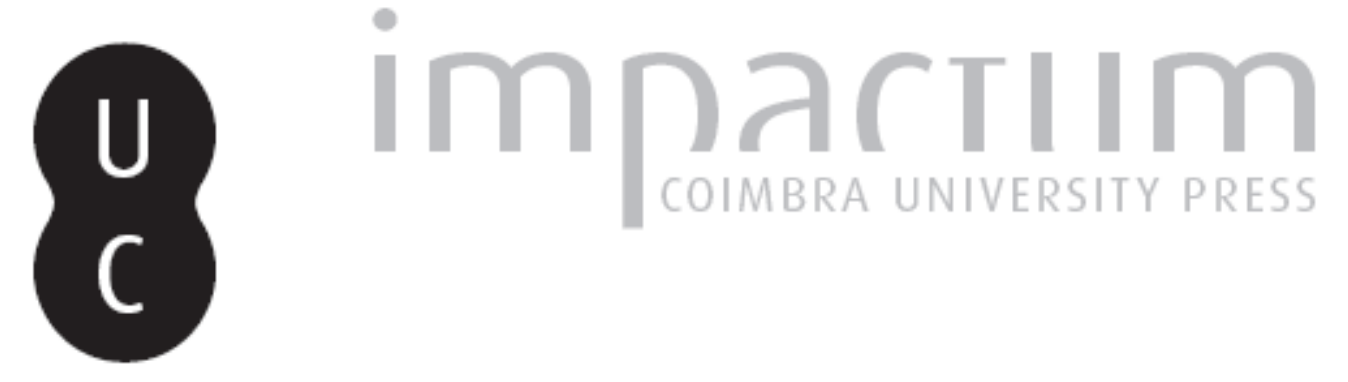

\title{
La recepción ideológica del salazarismo en España
}

\section{Autor(es): Cañellas, Antonio}
Publicado por: Faculdade de Letras da Universidade de Coimbra, Instituto de História Económica e Social

URL persistente:

URI:http://hdl.handle.net/10316.2/28194

DOI:

DOI:http://dx.doi.org/10.14195/0870-4147_43_15

Accessed : $\quad$ 26-Apr-2023 12:02:25

A navegação consulta e descarregamento dos títulos inseridos nas Bibliotecas Digitais UC Digitalis, UC Pombalina e UC Impactum, pressupõem a aceitação plena e sem reservas dos Termos e Condições de Uso destas Bibliotecas Digitais, disponíveis em https://digitalis.uc.pt/pt-pt/termos.

Conforme exposto nos referidos Termos e Condições de Uso, o descarregamento de títulos de acesso restrito requer uma licença válida de autorização devendo o utilizador aceder ao(s) documento(s) a partir de um endereço de IP da instituição detentora da supramencionada licença.

Ao utilizador é apenas permitido o descarregamento para uso pessoal, pelo que o emprego do(s) título(s) descarregado(s) para outro fim, designadamente comercial, carece de autorização do respetivo autor ou editor da obra.

Na medida em que todas as obras da UC Digitalis se encontram protegidas pelo Código do Direito de Autor e Direitos Conexos e demais legislação aplicável, toda a cópia, parcial ou total, deste documento, nos casos em que é legalmente admitida, deverá conter ou fazer-se acompanhar por este aviso.

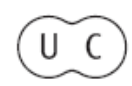





\title{
La recepción ideológica del salazarismo en España
}

\author{
Antonio Cañellas \\ Universidad de Navarra \\ acanellas@unav.es
}

\section{Resumen:}

La influencia del régimen de Salazar en España se dejó sentir desde los años treinta. La necesidad de la derecha católica de contar con referentes ideológicos ya institucionalizados como modelos en los que inspirar su proyecto de Estado, determinó la configuración de una corriente de pensamiento que resultaría crucial durante el franquismo. Herederos del tradicionalismo alfonsino que sostuvo a la dictadura de Primo de Rivera y que difundió sus ideas desde la revista Acción Española, los neotradicionalistas lograrían su continuidad por el testigo de una nueva generación. Si en las postrimerías de los años veinte ya se habían tendido puentes con el movimiento integralista, al compartir la dimensión católica de la alianza peninsular expuesta por Sardinha, ésta se perpetuaría al renovarse sus cuadros dirigentes llamados a integrar el entramado político de los regímenes ibéricos. Esta confluencia de pareceres se manifestaría en la idea corporativa del Estado y en su carácter misional en defensa de Occidente, dentro de la promoción del desarrollo económico como fuente añadida a una pretendida legitimación del sistema. Esta mutua recepción de criterios y procedimientos estaría vinculada a la respectiva madurez de sus modelos autoritarios, que variarían su influjo en función de su propia adaptabilidad.

Palabras clave:

Autoritarismo; Franquismo; Salazarismo; Sistema político.

\section{Abstract:}

The influence of Salazar's regime in Spain was apparent since the 1930s. The need for Spanish right-wing Catholics to have ideological references for their State project, determined the configuration of a current of thought that would flourish during Franco's regime. Heirs of the "alphonsine" traditionalism that supported Primo de Rivera's dictatorship and spread its ideas through the journal Acción Española, the new traditionalists continued into the following generation. In the late 1920s they approached the Portuguese Integralism, (with which they shared the catholic dimension of the Iberian alliance defended by António Sardinha), and pushed the renewal of leaders in both countries. This convergence would be expressed in the corporate State and its defence of Occident, with economic development as a symbol of the legitimacy of the system. This mutual reception of criteria and procedures would be linked to the maturity of their respective authoritarian models, varying their influence according to each one's adaptability.

Keywords:

Authoritarianism; Franquism; Salazarism; Political system. 


\section{La referencia de un modelo constitucional}

La ductilidad de la política de Salazar le permitió crear espacios de compromiso para federar bajo su jefatura a las distintas corrientes conservadoras que integraban el régimen ${ }^{1}$. De este modo, conseguiría convencer a los militares de la necesidad de institucionalizar el movimiento del 28 de mayo de 1926 con la promulgación de una nueva Constitución, que integrara los principios de un nacionalismo de orden autoritario como elementos definidores del Estado, inaugurando el primer sistema corporativo del mundo ${ }^{2}$.

Con el nombramiento de Salazar como Primer Ministro en 1932 se fue consolidando la línea autoritaria en el proceso de institucionalización política, a pesar de cierta semántica de origen liberal en algunos artículos destacados de la Constitución de 1933. En efecto, la adopción de soluciones eclécticas venía condicionada por la necesidad de articular una convivencia factible entre los distintos grupos ideológicos de la derecha que integraban el sistema, reunidos en torno al personalismo político del Presidente del Consejo, que otorgaría a dicha coalición la suficiente capacidad operativa para permitir la subsistencia prolongada de la Segunda República.

Sin embargo, la procedencia ideológica de Salazar y de sus colaboradores más cercanos posibilitó, de hecho, un avance considerable de las posiciones más estrictamente contrarrevolucionarias, ligadas al integralismo lusitano y al grupo del Centro Académico de la Democracia Cristiana, en cuanto a movimientos opuestos a los ideales de la modernidad. La respuesta del magisterio de la Iglesia frente a los llamados errores de la filosofía moderna, que habrían alterado el orden sociopolítico del antiguo régimen de Cristiandad o Ancien Régime, obligó a diseñar varias líneas estratégicas entre los católicos en su intento por restaurar los principios cristianos en las sociedades contemporáneas. Las posiciones defensivas y combativas, propias del tradicionalismo inmovilista, se simultanearon con otras de carácter posibilista que aspiraban a emprender la cristianización de los regímenes liberales desde sus propias estructuras. En este sentido, el Centro Académico de la Democracia Cristiana sería una expresión clara de esta última fórmula, especialmente animada desde el pontificado de León XIII, cuyas enseñanzas definirían el acervo doctrinal de un grupo que acabaría liderando Salazar durante la Primera República.

1 Fernando Rosas, Portugal siglo XX. Pensamiento y acción política, Mérida, Junta de Extremadura, 2004, p. 84-85.

2 Franco Nogueira, Salazar: Os tempos áureos 1928-1936, vol. 2, Coimbra,Atlântica editora, 1977, p. 206-207. 
Esta respuesta tradicionalista del catolicismo ante los retos de la modernidad, dentro de sus distintas modalidades y estrategias, convivió con otras surgidas de la propia cultura moderna, sobre todo después de la Gran Guerra a partir de 1918. En este caso, tanto el socialismo como el fascismo representarían dos exponentes ideológicos revolucionarios en la movilización de las masas, en su intento por superar las contradicciones del liberalismo. Así las cosas, puede hablarse de una cohabitación entre grupos tradicionalistas y fascistas, coincidentes en su crítica a la cosmovisión liberal, pero divergentes respecto a sus soluciones, a causa de un sustrato ideológico distinto. Si el tradicionalismo era, en origen, una ideología de reacción, contraria a los hitos de la revolución liberal y, a posteriori, de la revolución bolchevique, el fascismo era la consecuencia nacionalista de un socialismo despojado de sus tesis marxistas. Aunque convergentes en su expresión totalitaria, el comunismo cifraba su razón de ser en la abolición de las clases por la vía de la dictadura del proletariado y, en el segundo, en el papel central del Estado como agente configurador de la nación y del individuo.

Por poco que se repase la trayectoria de los regímenes ibéricos podrá comprobarse que el pensamiento político que los informa y define es de naturaleza tradicionalista, más allá de que adoptaran formas o expresiones fascistizadas, y que algunos autores han caracterizado bajo nomenclaturas y tipologías propias ${ }^{3}$. Una definición que como ha señalado Ernst Nolte o Stanley Payne $^{4}$, se correspondería a una particular variante nacional, coincidente con el máximo apogeo de la ideología fascista en Europa entre 1933 y 1944 aproximadamente. Prueba de este predominio ultraconservador, resultaría la neutralización del fascismo nacional-sindicalista de Rolâo Petro en 1934 por parte de las autoridades portuguesas, al objeto de guardar los equilibrios internos y preservar la unidad política del régimen, cada vez más decantado hacia un tradicionalismo no menos autoritario y deseoso de integrar a los nacional-sindicalistas, que acabarían asumiendo el control de la propaganda del Estado Novo ${ }^{5}$.

Algo parecido sucedería en España con el paulatino proceso de desfalangización a partir de 1944 y el triunfo escalonado de un proyecto tradicionalista,

3 Véase la interesante obra de Jorge Pais de Sousa, O fascismo catedrático de Salazar, Coimbra, Universidade de Coimbra, 2011.

4 Ernst Nolte, La crisis del sistema liberal y los movimientos fascistas, Barcelona, Península, 1971, p. 322-323; Stanley Payne, El fascismo, Madrid, Alianza, 1982, p. 143, 157-160.

5 Fernando Rosas (coord.), "O Estado Novo", en José Mattoso (direc.), História de Portugal, Vol. 7, Lisboa, Estampa, 1994, p. 184. 
que abogaba por la instauración de una Monarquía católica y corporativa apoyada por el desarrollo económico y la funcionalidad administrativa ${ }^{6}$.

En cualquier caso, la Constitución portuguesa de 1933 terminó creando un Estado que rechazaba la organización política del liberalismo, a pesar de reconocer todo un elenco de derechos ciudadanos que acabarían supeditados a las disposiciones legales dictadas por el poder absorbente del Ejecutivo. De todos modos, el modelo portugués se alejaba de las concepciones totalitarias europeas al limitar el poder con arreglo a la moral y el derecho ${ }^{7}$, adaptando las instituciones a la tradición histórica del país. La falta explícita de un designio totalizador por parte del Estado no contravenía su interés por lograr la conquista de las almas, en su objetivo por crear una nueva sociedad modelada en la uniformidad del pensamiento tradicionalista. En el fondo, se trataba de legitimar el poder como instrumento de acción pedagógica ${ }^{8}$, sobre una sociedad que debía desligarse de los esquemas mentales heredados del liberalismo. La vinculación oficial a los principios indiscutibles marcados por la trilogía Dios, Patria y Familia, encuadraría el pluralismo dentro de los estrictos límites de la concepción moral definida por el régimen. La abolición de los partidos políticos como cauce legítimo de participación política era la consecuencia lógica del planteamiento tradicionalista, cuya razón de ser radicaba en una percepción antropológica que definía al hombre como ser social, ligado a la permanencia de los principios históricos de la nación. Cabía, pues, restituir el principio político de la representación en las unidades y cuerpos sociales como alternativa del partidismo ${ }^{9}$, sin por ello renunciar al recurso de sufragio directo,

6 Entre la abundante bibliografía que corrobora esta tesis acerca de la contextura ideológica del régimen español merecen señalarse varios títulos: Gonzalo Redondo, Política, cultura y sociedad en la España de Franco (3 tomos), Pamplona, Eunsa, 1999/2005/2009; Álvaro Ferrary, El franquismo: minorías políticas y conflictos ideológicos 1936-1956, Pamplona, Eunsa, 1993; Pedro Carlos González Cuevas, El pensamiento político de la derecha española en el siglo XX, Madrid, Tecnos, 2005; Ismael Saz, Fascismo y franquismo, Valencia, Publicacions de la Universitat de València, 2004.

7 Antonio de Oliveira Salazar, Principios fundamentales de la revolución política, Lisboa, SPN, 1930, p. 77.

8 Hipólito de la Torre (coord.), España-Portugal. Estudios de Historia Contemporánea, Madrid, Editorial Complutense, 1998, p. 23.

9 "Las dudas suscitadas acerca de la posibilidad de una vida constitucional sin partidos políticos, provienen principalmente de la dificultad, creada por los hábitos adquiridos, de comprender que una máquina puede funcionar diferentemente a como fue vista funcionar durante más de un siglo. Está tan arraigado en nosotros el espíritu de grupo y tan poco el de nación, que, soluciones políticas, absolutamente lógicas dentro de la orientación nacional, no llegan a entenderse y son muchas veces criticadas por los mismos de cuyo espíritu no se puede 
aunque restringido, en la elección de los representantes políticos. De hecho, la Constitución también fijó la elección del Presidente de la República por el mismo procedimiento para un mandato renovable de siete años. La aportación realizada por los grupos más liberales de la dictadura se inspiraba en la influencia presidencialista del sidonismo ${ }^{10}$. No obstante, la necesidad de un equilibrio de poderes que garantizara la permanencia del régimen, determinó la existencia de un Jefe del Ejecutivo designado por el Presidente y que respondía ante él de las funciones de gobierno que tenía encomendadas por las disposiciones constitucionales. En la práctica, eso implicó una perpetuación de Salazar en el ejercicio del poder, que se vio reforzado por el control personal en la designación del candidato oficialista a la Presidencia de la República a partir de $1951^{11}$.

La preeminencia del Ejecutivo sobre los poderes deliberativos del Estado, no fue obstáculo para organizar la Cámara Corporativa como entidad de representación orgánica de la nación. A pesar de sus funciones consultivas, constituyó un modelo en el que se inspiraría el régimen de Franco para promulgar la Ley de Cortes de 1942.

La subordinación de aquélla a la Asamblea Nacional, elegida por sufragio directo en distrito nacional de entre las listas admitidas por el Gobierno, manifestaba otro intento por conciliar los rasgos del corporativismo tradicionalista con los esquemas del liberalismo conservador, además de cuidar la imagen de una supuesta legitimidad fundada en el formalismo legal. La ilegalización de los partidos forzaría la creación de asociaciones o movimientos que, con el beneplácito de las autoridades, acabarían actuando a modo de

dudar." Prólogo de Salazar en Antonio Ferro, Oliveira Salazar. El hombre y su obra, Madrid, Fax, 1935, p. 18.

${ }^{10}$ Es verdad que ciertas tendencias autoritarias del sidonismo han llevado a algunos autores a interpretarlo como la antesala del fascismo en Portugal, pero lo cierto es que, como apunta Ana Rodríguez, la República Nova carecía de cualquier pretensión totalizadora, al restablecer el pluralismo político y la celebración regular de sesiones parlamentarias. Ana Rodríguez Gaytán de Ayala, Orden en Portugal. La República Nova de Sidónio Pais (1917-1919), Mérida, Junta de Extremadura, 2006, p. 267.

${ }^{11}$ La conclusión de la indiscutida jefatura del Mariscal Carmona al frente de la Presidencia de la República (1951), fundada en su participación en el pronunciamiento militar de 1926, reorientó la legitimidad de los sucesivos candidatos en la designación directa de Salazar, confirmado como líder absoluto del régimen. Con la reforma constitucional de 1959 en la que el Presidente pasó a ser elegido por un colegio electoral restringido, se reforzaría el poder personal del Primer Ministro en respuesta a las movilizaciones organizadas por la candidatura opositora de Humberto Delgado en las elecciones presidenciales de 1958. 
partidos políticos durante el breve plazo de las campañas electorales ${ }^{12}$. El control ejercido por el Estado mediante los mecanismos de coacción y la utilización de la censura ${ }^{13}$, dificultaría la actuación de los grupos opositores fuera del período electoral. De este modo, la aplicación de la Constitución por parte del autoritarismo de la coalición gobernante, cercenaría las posibilidades de un texto ecléctico que admitía un hipotético desarrollo político de carácter liberal ${ }^{14}$.

Asimismo, la integración de todas las corrientes del sistema en el movimiento gubernamental de la Uniâo Nacional, favorecería la uniformidad de criterios bajo el liderazgo vigilante de Salazar. Es cierto que dicha organización se había formado siguiendo las líneas de la Unión Patriótica de Primo de Rivera ${ }^{15}$, pero estaba lejos de constituir un partido de masas. Más bien todo lo contrario, la Uniâo Nacional sirvió para encuadrar una parte de los efectivos humanos del régimen para el control de la maquinaria administrativa del Estado. No obstante, la convivencia de las distintas tendencias ideológicas, encontraría su equivalente español en el Movimiento Nacional como agrupación de fuerzas políticas antirrevolucionarias, sobre todo a partir de la reestructuración interna de 1945. En efecto, la victoria aliada forzaría una apertura del régimen portugués con elecciones más trasparentes, que exigían una mayor activación funcional de la Uniâo ante el proceso electoral ${ }^{16}$. De hecho, el riesgo a un hipotético triunfo

12 "Penso que estou na verdade mas o mundo todo assentou em que a existência de partidos é o sinal exterior oua prova provada da existência de instituçôes livres. Onde nâo há partidos nâo há liberdade, porque há entâo um só partido que monopoliza as possibilidades de governo e de opiniâo. Isto nâo me parece certo mas o pensar é geral." Carta de Salazar a Caetano (01/03/1947), en José Freire Antunes, Salazar e Caetano. Cartas secretas 1932-1968, Lisboa, Difusâo cultural, 1994, p. 214.

13 "Recurrimos a la censura para no permitir a cualquiera y a todo el mundo que envenenen el espíritu público y perturben la concordia nacional.” Declaraciones de Salazar al semanario Aspects de la France (20-julio-1958). Archivo Francisco Franco (AFF), doc 13221. La utilización de los instrumentos censores pretendía integrar a la población en el pensamiento moral que, según las autoridades, debía regir la vida del país. El Secretariado da Propaganda Nacional se había creado en 1933 con el objetivo de popularizar los principios ideológicos del Estado Novo, en contraposición a la difusión de las ideas democráticas, acusadas de alterar la paz de la comunidad nacional en beneficio de los intereses partidistas. Véase Alberto Pena, El gran aliado de Franco. Portugal y la Guerra Civil española, La Coruña, Ediciós do Castro, 1998. Antonio César Moreno Cantano, Los servicios de prensa extranjera en el primer franquismo 1936-1945, (tesis inédita), Universidad de Alcalá de Henares, 2008, p. 182-188.

${ }^{14}$ Manuel Braga da Cruz, "El modelo político salazarista" en Hipólito de la Torre (coord.), Portugal y España en el cambio político (1958-1978), Mérida, UNED, 1990, p. 40-41.

${ }^{15}$ Stanley Payne, Breve historia de Portugal, Madrid, Playor, 1987, p. 182-183.

16 "La orientación política [de Portugal] es siempre la misma, si bien con una acentuación más marcada de los principios que informan sobre todo lo que toca al régimen corporativo. [...] Los elementos y partidos de izquierdas que viven en la clandestinidad comienzan a agitarse a 
del movimiento antisalazarista fue contestado en España con la introducción de un sistema orgánico de representación a través de las Cortes. Con arreglo al artículo 2, se asignaba a la Cámara la función de preparar y elaborar leyes, en cuyos trabajos participarían los representantes del Sindicato, el Municipio, la Provincia y los Cuerpos profesionales contemplados en la ley, como los procuradores designados por el Jefe del Estado en un número no superior a cincuenta. Con ello Franco ejercía una influencia directa sobre un ámbito del que ya disponía de la suprema potestad para dictar normas jurídicas de carácter general, conferida por la Ley del 30 de enero de 1938 y confirmada tanto en el preámbulo de la Ley de Cortes como en su artículo 17, por el cual el Jefe del Estado podía vetar las iniciativas legislativas de la Cámara, devolviéndolas para un nuevo estudio ${ }^{17}$.

Esta delegación de funciones por parte del Jefe del Estado apenas ahondaba en una representatividad real por parte de los integrantes de las Cortes, debido a que la mayoría de procuradores estaban ligados de una forma u otra al nombramiento del Ejecutivo; sobre todo los cargos sindicales y alcaldes que eran designados directamente por el Gobierno. Sólo a medida que fue consolidándose el régimen se abriría un proceso paulatino de apertura que intentaría encauzar las transformaciones sociales operadas durante la era del desarrollo económico. Entre otras, una mayor liberalización en la elección directa de los procuradores del llamado tercio familiar, que pasaría a reestructurar la composición de las Cortes a partir de 1967.

El cambio en el escenario internacional con la derrota de los países del Eje motivaría la introducción en España de una serie de medidas legales enfocadas a asegurar la permanencia del sistema. La Ley del 17 de julio de 1945 por la que se aprobaba el Fuero de los Españoles intentó dar al Régimen un contenido jurídico más objetivo y de garantías civiles que atrajeran a nuevo personal político para intensificar la imagen católica en el exterior, con el objeto de disminuir la hostilidad de los regímenes liberales ${ }^{18}$. De este modo pudieron sintetizarse los hitos principales del Derecho tradicional español fundados en el pensamiento escolástico sobre la condición privativa de la persona que,

medida que evoluciona la situación política mundial. [...] Por los informes obtenidos [...] parece ser que el Partido Comunista comienza a agitarse buscando enlaces con elementos españoles." Informe sobre política interna (21 diciembre 1944). Archivo del Ministerio de Asuntos Exteriores (AMAE), leg 2303, exp. 6.

${ }^{17}$ Puede también apreciarse esta comparativa con el caso portugués en el estudio de Manuel Loff, "Salazarismo e franquismo: projecto, adaptaçâo e História”, en Revista de História das ideias, no 31, Coimbra, 2010, p. 474-475.

${ }^{18}$ Stanley Payne, El régimen de Franco, Madrid, Alianza, 1987, p. 362. 
por su propia naturaleza, comportaba obligaciones morales y sociales en beneficio de la comunidad, primando los deberes como pauta imprescindible para el recto ejercicio de la libertad ${ }^{19}$, coincidente en este punto con el principio inspirador del artículo 4 de la Constitución portuguesa de 1933, que limitaba los poderes del Estado en orden a la moral y el derecho. Ciertamente, aunque esta noción no eludía los derechos y deberes inherentes a la persona, enfatizaba su dimensión social. De ahí que las corporaciones fueran, a efectos jurídicos, las auténticas depositarias del derecho, pudiendo beneficiarse el individuo en cuanto integrante de las mismas. Es claro que esta perspectiva sociedalista, que atribuía a la comunidad unos fines superiores a la de los intereses individuales, contravenía la visión filosófica del individualismo positivista, inclinado hacia una concepción autosuficiente de la persona, que carecería del recurso a los axiomas morales ligados a la norma objetiva dada por la naturaleza.

De acuerdo con las aportaciones de León Duguit, Edmund Husserl o Georg Friedrich Hegel, pensadores como Ramiro de Maeztu o los tribunos del integralismo lusitano, cifraban el valor de las esencias nacionales en el reconocimiento del espíritu objetivo. Éste resultaría de la realidad dominante a lo largo de la historia, remitiendo por elevación al catolicismo, como apuntaron los pensadores peninsulares, al significar el principio superior por el que debería regirse la comunidad. Su función consistiría en informar el entramado social, desde una tradición continuada y mejorada por la acción de las sucesivas generaciones como respuesta a la fuerza de su imperativo moral ${ }^{20}$.

Esta similitud entre las categorías políticas del pensamiento tradicionalista peninsular sentaría las bases para una fructífera colaboración entre dos regímenes inspirados en esos criterios. En realidad se trataba de una prolongación de los esquemas filosóficos al plano institucional, llevado a cabo por la acción concatenada de las generaciones herederas de aquella teología política. De ahí que sus jóvenes pregoneros destacaran las comunes raíces ideológicas de los sistemas peninsulares ${ }^{21}$, reclamando una mutua cooperación en el plano del ordenamiento jurídico, con un concepto misional del Estado que aspiraban a trasladar al ámbito de las relaciones exteriores. El interés por

${ }^{19}$ Luis Suárez, Franco. Proyectos para una doble estabilización, Madrid, Actas, 2001, p. 25.

${ }^{20}$ Véase sobre este punto la obra de Pedro Carlos González Cuevas, Maeztu. Biografía de un nacionalista español, Madrid, Marcial Pons, 2003, p. 312.

${ }^{21}$ Alfredo Sánchez Bella, "Panorama del pensamiento político portugués", en Revista de Estudios Políticos, n 15, Madrid, 1944, p. 161. 
la temática portuguesa, recogida en algunas publicaciones monográficas de distintas revistas españolas, partía de la representación del Estado Novo como un modelo constitucional acabado en el que inspirar buena parte del proceso institucionalizador pendiente en España. Las referencias tempranas acerca de la técnica jurídica aplicada en Portugal y esbozada en algunos artículos de Laureano López Rodó ${ }^{22}$, en estrecha conexión con el administrativista Marcelo Caetano, quien le autorizaría a traducir al español su principal obra Tratado elemental de Derecho Administrativo en 1946 con notas de derecho español comparado ${ }^{23}$, demuestran la atención por las aportaciones lusas en ese terreno. Una tesis confirmada por otros organismos españoles de reciente creación como el Instituto de Cultura Hispánica, que incluiría entre sus departamentos un Seminario de Problemas Actuales Hispanoamericanos con una sección específica dedicada a las relaciones culturales con Portugal. El hecho de que su dirección recayera en el Catedrático de Historia de América de la Universidad de Sevilla, Florentino Pérez Embid, denota la influencia de los grupos tradicionalistas ligados a la revista Arbor del Consejo Superior de Investigaciones Científicas y a la colección de la Biblioteca de Pensamiento Actual de las ediciones Rialp, de la que actuaría como secretario adjunto. En cualquier caso, sus responsabilidades al frente de aquella área le permitirían cursar la petición formal al Secretario Nacional de Propaganda, Información y Turismo de Portugal, Tavares de Almeida, para disponer de todo tipo de materiales relacionados con la organización corporativa del Estado portugués, su política colonial, su acción social o sus problemas espirituales y religiosos, con el ánimo de conocerlos y divulgarlos en España a través de las páginas de la revista Cuadernos Hispanoamericanos ${ }^{24}$, integrada en la estructura del Instituto de Cultura Hispánica.

${ }^{22}$ Véase Laureano López Rodó, "La obra del Profesor Marcelo Caetano", en Revista de la Facultad de Derecho de Madrid, n $^{\circ}$ 13, Madrid, 1944, p. 167-177.

23 "Por fin han llegado hoy a mi poder los primeros ejemplares de la edición española de su Tratado de Derecho Administrativo y me apresuro a enviarle en correo urgente un volumen [...]. Espero que la traducción sea de su agrado, así como las notas que le he añadido para acoplarla al Derecho español. No dudo que la obra será muy bien recibida por el público, que sabrá disculpar la publicación fraccionada en atención a las actuales circunstancias. Ya le tendré a usted al corriente de los comentarios que aparezcan en las distintas revistas jurídicas." Carta de Laureano López Rodó a Marcelo Caetano (diciembre, 1946), en Archivo General de la Universidad de Navarra, fondo: Laureano López Rodó (en adelante, AGUN/LLR).

${ }^{24}$ Carta de Florentino Pérez Embid a A. Tavares de Almeida (26/09/1947). Archivo General de la Universidad de Navarra, fondo: Alfredo Sánchez Bella. AGUN/ASB. 
La preocupación constante por garantizar la estabilidad y equilibrio de los dos regímenes a ambos lados de la frontera peninsular, radicaba en la necesidad de un apoyo mutuo frente a las hostilidades internas y exteriores. Más aún teniendo en cuenta el papel protagonista que deseaban asumir en las áreas geográficas de tradicional influencia, proyectando su cosmovisión católico-tradicionalista en la definición de la sociedad y del modelo de Estado correspondiente. El aislamiento internacional al que se vería sometida España al poco de concluir la Segunda Guerra Mundial, enervó las protestas de los partidarios del régimen ${ }^{25}$, al tiempo que condicionó la respuesta de la diplomacia para preservar los acuerdos suscritos con Portugal y evitar el bloqueo absoluto en el plano exterior. Sin embargo, las reformas aperturistas que tuvo que asumir el Gobierno de Salazar ante la oleada democratizadora desplegada en Occidente, alarmó a la Embajada española en Lisboa, que subrayó el peligro de un posible vuelco político en el país vecino, cuya repercusión podía alterar la propia continuidad del Estado franquista:

Desde que se celebraron las elecciones, las izquierdas han empleado la táctica de minar por todos los medios posibles la confianza del pueblo en el Gobierno; de laborar en reserva y obstaculizar toda gestión que puedan. [...] Los comunistas también se mueven armónicamente con los citados y se asegura que existe bastante relación con las organizaciones españolas $^{26}$.

Unas informaciones en parte confirmadas por la carta de Caetano remitida a López Rodó el 25 de noviembre de 1945 en la que, aún reconociendo la movilización opositora, advertía que esas dificultades habían fortalecido al Estado Novo ${ }^{27}$. Las aseveraciones dirigidas a su colega de la Universidad de Santiago de Compostela, eran el resultado de una previa operación de reestructuración de la Uniâo Nacional, destinadas a evitar la quiebra del

25 "En España, pese a la UNO [Naciones Unidas], miramos con confianza al porvenir porque, como decían algunas pancartas de las grandiosas manifestaciones de protesta celebradas días pasados, recordando un viejo refrán castellano, "la UNO propone y Dios dispone". Lo más característico de estas reacciones populares fue el buen humor reinante. Los españoles hemos tomado a broma todo lo ocurrido. Fue todo una farsa, pero "una farsa en la que se oía demasiado al apuntador" (copio de otra pancarta). Y nuestra protesta burlona era la mínima reacción seria y digna que cabía." Carta de Laureano López Rodó a Marcelo Caetano (sin fecha). AGUN/LLR.

${ }^{26}$ Informe sobre la situación general de Portugal, 1946. Archivo Francisco Franco (AFF), doc. 14044.

27 "Vim encontrar a agitaçâo eleitoral no máximo, mas o país manifestou-se a favor de Salazar, e emhora a oposiçâo tenha revelado combatividade estou certo de que o Estado Novo prosseguirá.” Carta de Marcelo Caetano a Laureano López Rodó (25/11/1945). AGUN/LLR. 
sistema portugués ante la previsible embestida de la oposición en las elecciones legislativas de 1946. Para ello se acordó que los órganos ejecutivos centrales de la Uniâo Nacional, pasaran a reunirse en comisión con la agregación de las secciones de propaganda, distritos y colonias. El propósito era movilizar la organización para concurrir con eficacia en la campaña electoral y vencer por amplia mayoría. Un activismo que, de la mano de Caetano, acabaría reconociendo toda una variedad de asociaciones culturales y patrióticas integradas al amparo del espíritu de aquel movimiento, permitiendo la reunión de grupos políticos diversos dentro de una afinidad que debía converger en el acatamiento a los principios fundamentales del Estado Novo ${ }^{28}$. El recurso a la Uniâo Nacional como instrumento de movilización social al servicio del régimen, respondía a las directrices marcadas por Salazar. De este modo, una vez cubiertos los objetivos de asegurar el triunfo de la candidatura oficialista en las elecciones presidenciales de 1949, se dio por concluida la misión de Caetano al frente de la Comisión Ejecutiva de la organización ${ }^{29}$. Logrado el apuntalamiento del sistema hasta la crisis de 1958, pareció abrirse una etapa de convivencia en el seno del salazarismo entre las corrientes inmovilistas y las liberalizadoras, representadas entonces por el espíritu reformista de Caetano ${ }^{30}$. Esta mayor seguridad facilitó el respaldo diplomático de Portugal al régimen español en unos momentos de aislamiento internacional. El viaje oficial de Franco a tierras lusas en octubre de 1949 sirvió para estrechar lazos con el Estado Novo. Su investidura como Doctor Honoris Causa en Derecho por la Universidad de Coimbra manifestó la clara sintonía ideológica entre Lisboa y Madrid, al reconocer los méritos de Franco en la guerra de España y en la conflagración mundial ${ }^{31}$, por cuanto había garantizado la estabilidad del área peninsular. A este reconocimiento se sumaba el intento de las autoridades portuguesas por compensar la exclusión de España del Pacto Atlántico suscrito en abril. El interés de Portugal por adherir a España a la OTAN se debía a la necesidad de cubrir mejor su flanco oriental ante un hipotético ataque soviético, sin descuidar el aliciente ideológico que hubiera supuesto su ingreso para contrarrestar la influencia del liberalismo, ante la proclama democrática recogida en el preámbulo del Pacto. No obstante, la lectura de Salazar se ceñía al estricto cumplimiento de los compromisos

\footnotetext{
${ }^{28}$ Marcelo Caetano, Minhas memórias de Salazar, Lisboa, Verbo, 1977, p. 306.

${ }^{29}$ Carta de Marcelo Caetano a Laureano López Rodó (17/04/1949). AGUN/LLR.

${ }^{30}$ Juan Carlos Jiménez Redondo, "Liberalización...”, cit., p. 536.

${ }^{31}$ Proclama recogida en el suplemento especial de la revista Mundo Hispánico, no 20, noviembre, 1940.
} 
militares para la defensa de Occidente ${ }^{32}$ que, en su opinión, terminaría por comprender quiénes eran verdaderamente sus defensores ${ }^{33}$, justificando su propia posición y la de España en virtud de su común esencia ideológica.

Cuestión que incentivó ese reconocimiento de una pluralidad interna dinamizada por la Uniâo Nacional, tomada como modelo por parte de ciertos sectores del tradicionalismo español para recuperar el pluralismo inicial del Movimiento, frente al predomino político asumido por la Falange. Al igual que en Portugal, quiso primarse la centralidad del Gobierno con el recurso a un burocratismo autoritario que, como apuntó Braga da Cruz para el caso portugués, perfilaría los rasgos de una dictadura administrativa o burocrática ${ }^{34}$.

Nuevamente, la influencia del Estado Novo en este punto encontraría solución de continuidad en las jóvenes generaciones tradicionalistas, instruidas en el pensamiento de los años treinta. En efecto, tanto Víctor Pradera ${ }^{35}$ como Eugenio D’Ors y Félix Correa actuarían de altavoces del ideario salazarista en España. Su aversión a la que consideraban como decadencia del parlamentarismo se contraponía a la defensa del Estado social corporativo, como alternativa para el progreso ordenado de los pueblos, de acuerdo con las realidades emanadas de la naturaleza humana ${ }^{36}$. El recurso al "político de misión" requería de la unidad de mando en el manejo de los resortes del Estado para transformar la sociedad $^{37}$. Sólo así la administración podría convertirse en el brazo ejecutor del Gobierno para desarrollar con eficacia su particular tarea regeneradora.

${ }^{32}$ Fernando Rosas (coord.), "O Estado Novo”, en José Mattoso, História..., cit., p. 401.

${ }^{33}$ Declaraciones de Salazar recogidas en Mundo Hispánico, noviembre 1949.

${ }^{34}$ Manuel Braga da Cruz, O Partido e o Estado no salazarismo, Lisboa, Presença, 1988, p. 255.

${ }^{35}$ La publicación en 1935 de El Estado nuevo de Víctor Pradera, inspiraba su título en la definición del Estado portugués y recogía la síntesis del pensamiento tradicionalista en España, subrayando su crítica al liberalismo y a los nacionalismos periféricos. La aportación de Pradera destacaría tanto por su relación ideológica con el pensamiento del General Franco, como por la continuidad intelectual ejecutada por las nuevas generaciones tradicionalistas. Véase José Luis Orella, Víctor Pradera. Un católico en la vida pública de principios de siglo, Madrid, BAC, 2000.

${ }^{36}$ Félix Correa, El Estado nuevo portugués, Zaragoza, Heraldo, 1938, p. 28.

37 "El político de misión al operar sobre un país civilizado, inclusive sobre un país de larga tradición en la cultura, lo hace al modo del misionero ocupado en redimir a un pueblo bárbaro de su barbarie. Lejos de obedecer a los instintos espontáneos de éste, el misionero los contrariará, corregirá, castigará, en el más noble sentido de la palabra.” Prólogo de Eugenio D’ors en Ferro, Oliveira Salazar..., cit., p. 12-13. 


\section{Cooperación a dos bandas: hacia una influencia mutua}

La fluidez de las relaciones entre España y Portugal, una vez constituido el régimen de Franco, se inscribía en el antiguo ideal de la alianza peninsular patrocinada por las corrientes del tradicionalismo ibérico durante los años treinta. Sin menoscabo de la independencia y soberanía propia, la aproximación de intereses sobre una base ideológica común extrapolada al ámbito internacional definiría la característica de ese actuar conjunto, sobre todo en las áreas geográficas de tradicional influencia.

Con todo y aún con la firma del Tratado de Amistad y de No Agresión en 1938, en el que se pretendió hermanar a las dos naciones en su lucha contra el comunismo, no dejaron de producirse algunos roces en el desarrollo del conflicto mundial. Sobre todo a causa de una neutralidad portuguesa que no dejaría de colaborar con sus aliados ingleses, lo cual preocuparía a los sectores más fascistizados del régimen español, por cuanto temían una hipotética intervención armada de las fuerzas británicas a través del territorio portugués con el fin de frenar la influencia del Reich en España. No es de extrañar que ante tal sospecha, el Estado Mayor del Ejército español elaborara un proyecto para la invasión de Portugal en 1940, que pretendía neutralizar cualquier acción de los aliados en la Península en un intento por reforzar la defensa nacional por medio de una intervención directa, que supliera la escasa potencialidad militar portuguesa mediante el control directo de toda la costa atlántica ${ }^{38}$.

La superación de la coyuntura bélica a partir de 1945 permitiría a los dos países ahondar en su común vocación por construir la nueva civilización cristiana, como premisa para el resurgimiento nacional ${ }^{39}$. Así, en el caso de

${ }^{38} \mathrm{AFF}$, doc 2803. El proyecto implicaba el incumplimiento de los acuerdos suscritos en el Protocolo Adicional de 1939, que obligaba a los dos Estados a no realizar ningún acto de agresión o invasión contra la otra parte (art 1). Sin embargo, la mutua dependencia de los regímenes peninsulares de cara a su futura supervivencia, facilitó el cumplimiento de los compromisos adquiridos con el mantenimiento de la neutralidad. Con todo, el distinto grado de colaboración de cada país con los bloques beligerantes condicionaría su posterior integración en el nuevo orden internacional, marcando la evolución de su política interna. Véase César Oliveira, Salazar e a Guerra Civil de Espanha, Lisboa, O jornal, 1988, p. 354-355.

39 "Esta nueva visita [...] es la expresión pública y solemne de una sentida y real compenetración entre nuestras dos naciones, que si al correr de los años pudo haber sufrido sus naturales eclipses, desde nuestra Cruzada de Liberación viene afianzándose y enraizando en el espíritu de nuestros pueblos." Discurso de Franco con ocasión de la visita a Madrid del Presidente de la República portuguesa, General Craveiro Lopes en 1952. AFF, doc 6438. Véase también Juan Carlos Jiménez Redondo, Franco e Salazar. As relaçôes luso-espanholas durante a Guerra Fria, Lisboa, Assírio/Alvim, 1996, p. 84. 
las relaciones con la Iglesia, los países peninsulares optarían por diferentes soluciones en razón de su trayectoria histórica. Portugal se inclinaría por una estrecha colaboración con la Iglesia contemplada en el Concordato de 1940 que, no obstante, salvaba la aconfesionalidad y la libertad de cultos, aún cuando en 1935 se había admitido la religión y la moral católicas como las tradicionales del país, a efectos de la enseñanza pública. Para Salazar el Concordato implicaba la definitiva normalización de las relaciones del Estado con la Iglesia, asegurando su mutua independencia con arreglo al principio de separación ${ }^{40}$.

Por el contrario, el Concordato de España con la Santa Sede (1953) consagraría la unión de la Iglesia y el Estado como pauta para la estructuración del régimen monárquico tradicional al que se aspiraba. La atención prestada por el franquismo a las negociaciones de Portugal con el Vaticano se inscribía en su interés por llegar a un rápido entendimiento con la Iglesia. La rúbrica del Convenio de 1941 representaba un modus vivendi en las relaciones a dos bandas entre la Iglesia y el régimen de Franco que, si bien se comprometía a restaurar «el sentido católico de la tradición nacional» a tenor de lo dispuesto en el punto sexto, la Iglesia quedaba a la prudente espera de ver consolidadas las instituciones del sistema, en vista de las dificultades en los equilibrios internos de poder, agravadas por los condicionantes del desarrollo bélico en Europa. También es verdad que la íntegra dimensión tradicionalista que quería imprimirse al nuevo Estado no estaba dispuesta a aceptar un modelo concordatario con reminiscencias liberales. En este sentido, se descartó la reedición de los acuerdos de 1852, como ya había clarificado el Convenio, al retomar el concepto sacro y tradicional del Estado católicamente constituido, en línea con las enseñanzas clásicas de la escolástica. De ahí que la misión del poder temporal consistiera en ordenar la sociedad conforme a la razón de la ley natural, integrada en la expresión sublime de la verdad revelada, a decir de la filosofía tomista ${ }^{41}$, lo cual justificaría la confesionalidad efectiva del Estado en

${ }^{40}$ Declaraciones de Salazar, en Cristine Garnier, Vacaciones con Oliveira Salazar, Madrid, Editorial Católica, 1953, p. 191.

${ }^{41}$ Tomás de Aquino, De Regimine Principium, Libro I, Capítulo VI. Por su importancia en el método de razonamiento y en su visión de la vida humana, el tomismo sirvió de fundamento filosófico para que la Escuela de Salamanca del siglo XVI desarrollara toda una serie de disquisiciones centradas en el sentido y la significación del derecho natural, considerando sus implicaciones en el ámbito de la legislación civil. En los tratados De iustitia y De potestate civili de Francisco de Vitoria, como en el De legibus de Francisco Suárez, queda claro el valor vinculante de la ley natural en el derecho positivo, que si bien no la instituye, debe reconocerla para adquirir fuerza de autoridad, en tanto se ordena al bien común de la res publica. Aunque esa función propia de la potestad civil no exigiría necesariamente la adhesión a la fe cristiana de los gobernantes, por estar circunscrita al recto ejercicio de la razón, la hacía del todo conveniente 
aquellas naciones de mayoría católica. Como ha apuntado Gonzalo Redondo, para Franco cabía promover una política que descansara en la Ley de Dios ${ }^{42}$, consecuencia de una visión que consideraba el hecho nacional y su sustrato religioso como dos caras de una misma moneda. Es decir, no se podía entender la una sin la otra, porque a juicio de esta postura esencialista, aquélla se integraba de manera consustancial para conformar una única realidad ${ }^{43}$. Cuestión que determinaría la postura del régimen en sus relaciones con la Iglesia:

En el conjunto de los artículos se puede observar el deseo de hacer resaltar la entera libertad reconocida a la Iglesia Católica con arreglo al nuevo Concordato. Concordato como el portugués, calcado en el vigente Código canónico, son los que la Santa Sede querría firmar con todos los países. Acaso los artículos de L'Observatore Romano miren a impresionar la opinión pública española, aunque saben muy bien en el Vaticano que el caso de España es completamente distinto, pues las concesiones pactadas con Portugal no se aproximan, ni con mucho, a las hechas unilateralmente por España ${ }^{44}$.

debido a las propias limitaciones humanas. La complementariedad entre razón y fe permitiría profundizar en la realidad antropológica, asistida por la autónoma cooperación de la Iglesia y del Estado en sus respectivos campos, dentro del principio de unidad que definiría los rasgos particulares de ese régimen de Cristiandad. La continuidad de estos planteamientos entre buena parte de los pensadores católicos de la época contemporánea, estuvo animada por los intentos de restaurar la filosofía cristiana según los criterios propuestos por León XIII en su encíclica Aeterni Patris Filius de 1879. Una línea que contribuiría a redefinir la concepción del derecho en virtud de la norma moral dada por la inmutabilidad de la naturaleza, y que en este punto se oponía a las consideraciones de la cultura moderna, perfilando un contraste entre una visión teocéntrica que haría de Dios la medida del hombre y una segunda, fundada en el antropocentrismo inmanente, que consideraría al hombre medida de todas las cosas, según la antigua sentencia de Protágoras. Tanto el Centro Académico de la Democracia Cristiana (CADC) en Portugal como la Asociación Católica Nacional de Propagandistas (ACNdP) en España responderían simultáneamente a ese intento por recristianizar la vida intelectual y de la opinión pública, para luego saltar al plano político con la organización del Centro Católico y de la CEDA como dos grandes partidos del electorado católico-conservador.

${ }^{42}$ Gonzalo Redondo, Política, cultura y sociedad en la España de Franco. La configuración del Estado español, nacional y católico (1939-1947), Vol. 1, Pamplona, Eunsa, 1999, p. 67.

${ }^{43}$ Son múltiples las obras de pensadores españoles de la época contemporánea que abundan en esta idea, inserta en los polémicos debates entre la concepción católica de la cultura tradicional y la surgida de la modernidad. En el contexto de profundos cambios en las que convivieron estas dos dimensiones, se tendió a una fuerte contraposición que, una vez elevadas al ámbito político, concluirían en sucesivos enfrentamientos civiles hasta su última eclosión en julio de 1936.

${ }^{44}$ Carta del embajador de España en Lisboa a Francisco Franco (13/06/1940). AMAE, leg 3460, exp. 17. 
De cualquier manera, la complementariedad ideológica de fondo facilitaría la profusión de contactos a todos los niveles entre Portugal y España, repercutiendo en una influencia recíproca creciente, en la que el régimen de Madrid acabaría recogiendo el testigo, incluso más logrado, del prototipo de Estado tradicionalista con aspiraciones proyectivas en el ámbito internacional ${ }^{45}$.

Como se ha dicho, la teorización del Estado autoritario formulada por Salazar influiría notablemente en la derecha española contrarrevolucionaria. Sin embargo, sería Marcelo Caetano quien asumiría la actualización y desarrollo de unas tesis que se incorporarían al elenco doctrinal de la generación neotradicionalista, reunida en torno al CSIC y la revista Arbor. La fundación de dicha iniciativa cultural en 1944, respondía al deseo de integrar las distintas ramas del saber científico de acuerdo con las pautas de la filosofía escolástica, en su empeño por armonizar la fe y la razón. En el fondo, esta idea renacía de la adhesión a los valores intrínsecos del Alzamiento, en su pretensión por restaurar el orden católico tradicional. La progresiva articulación entre los componentes de Arbor de una minoría dirigente capaz de constituir una nueva vía en la institucionalización del régimen, facilitó la recepción de unos planteamientos que reforzaron su línea de pensamiento. Los argumentos expuestos por Caetano en las páginas de la revista (1949), confirmaron la renovación de las tesis autoritarias por el recurso explícito a la técnica de gestión como elemento de legitimación del Estado corporativo. Para el Catedrático portugués, la superación del individualismo liberal debía concluir en la inauguración de una dinámica corporativa de la comunidad, organizada en las instituciones del país.

45 "Franco e Salazar tinham em comum, a partir de horizontes culturais e vitais distintos, un mesmo fundo nacionalista, católico conservador, tradicionalista [...] o autoritarismo político, a aversâo ao parlamentarismo, a os partidos [...] optaram por câmaras corporativas, por uma burocracia estatal bastante centralizada [...] e ambos optaram de algum modo uma forma de "partido único" Joâo Medina, Salazar e Franco. Dois ditadores, duas ditaduras, Cascais, Curso Internacional de Verâo, 1996, p. 161-162.

Con motivo de la condena de la ONU al régimen español (1945), se manifestaría la solidaridad de Portugal de acuerdo al común ideario tradicional y antimarxista. Los intentos reiterados de Lisboa por integrar a España en la OTAN se debían a su interés por constituir un bloque homogéneo, capaz de combatir la influencia comunista en la Península: "Sobre Espanha desencadenou-se uma tempestade de insanidade e estulticia, soprada pelo comunismo e pela maçoneria internacionais, nâo para fazer a felicidade do povo espanhol, mas para maior grandeza do Tsar de todas as Russias...soviéticas. O fidalgo, cavalheiresco e generoso carácter espanhol nâo se deixará certamente conmover pelas cómicas votaçôes da ONU, a mais desacreditada assembleia internacional que jamais reuniu no orbe. No mundo sopra um vento de infamia! Até quando? Conseguirá a Peninsula deter mais esta onda de inféis que amenaça Europa?" Carta de Marcelo Caetano a Laureano López Rodó (06/01/1947). AHUN/LLR. 
Con todo, el particularismo corporativo necesitaría el contrapeso de un Gobierno independiente, fundado en la autoridad y la técnica para concentrarse en las tareas administrativas de gestión, dentro del ideal del Estado moderno ${ }^{46}$. Sólo así podría justificarse la pérdida del poder deliberativo de las asambleas, reducidas a una mera función consultiva, de acuerdo con su composición orgánica.

Sin embargo, estas reflexiones no determinaban el sometimiento de las instituciones a una "dictadura de expertos", en tanto que el valor técnico del gobierno debía encuadrarse dentro de los márgenes de unos principios políticos superiores, definidores de todo el entramado estatal ${ }^{47}$. La aportación de Caetano consistió en presentar un modelo tecno-autoritario para la organización política de la nación, con arreglo a la experiencia funcional portuguesa de 1933. No se trataba tanto de levantar un estamento técnico en los resortes del Estado, como de estructurar una nueva clase política, imbuida de una elevada tecnicidad para el mejor servicio de la sociedad, de acuerdo con los principios de una teología política de orden tradicionalista ${ }^{48}$. La correspondencia de dicho discurso con la línea de pensamiento patrocinada por Arbor, radicaba en la actualización del modelo tecnocrático auspiciado por la dictadura de Primo de Rivera. De este modo, las referencias al orden político tradicional se conjugarían con los factores de la eficacia técnica, con el aumento del aparato burocrático y el intervencionismo económico como elementos reguladores del crecimiento y la promoción social. La aplicación de este esquema se circunscribía a un proyecto de socialización conservadora, destinado a legitimar el Estado autoritario con arreglo a su funcionalidad competencial.

\section{Las repercusiones del reformismo tecnocrático}

La aportación portuguesa en este campo radicaba en la capacidad de conciliar su visión nacionalista de la economía ${ }^{49}$ con la aplicación de ciertas ideas tecnocráticas importadas por Francia a Europa desde los Estados

${ }^{46}$ Marcelo Caetano, "El problema de la representación política", en Arbor, n 43-44, 1949, p. 453.

47 "Ya antes advertimos la tendencia contemporánea del Gobierno a revestirse cada vez más de un carácter administrativo y técnico. Esto, en cierto modo, resulta beneficioso; pero tiene sus inconvenientes. [...] Para el técnico, todo se subordina al deber y a la alegría de ejecutar. Por eso es necesario corregir los excesos del tecnicismo mediante el funcionamiento de órganos específicamente políticos." Ibidem, p. 456.

48 Juan Carlos Jiménez Redondo, "Liberación versus democracia: tecnócratas y tecnocracias en la Península Ibérica (1959-1975)”, Revista de História das ideias, n 31, Coimbra, 2010, p. 544.

${ }^{49}$ Fernando Rosas, Salazarismo e fomento económico, Lisboa, Noticias, 2000, p. 24. 
Unidos, que imprimían un sentido técnico a la concepción y funcionamiento de la administración pública para el sostenimiento del régimen político ${ }^{50}$. Esta recuperación del legado reformista de la Monarquía autoritaria auspiciada por Joâo Franco a comienzos del siglo $\mathrm{XX}^{51}$, se reforzaría con la incorporación de modernas doctrinas que sustraían a la administración de la fiscalización de las asambleas y de la opinión pública. De este modo, toda vez que la reforma constitucional de 1933 definió la primacía del Gobierno por encima de los poderes deliberativos del Estado, la administración se erigiría en el instrumento independiente para asegurar la disciplina en los servicios públicos ${ }^{52}$. Ello no suponía concebir la política administrativa de modo estanco, ya que estaría ligada por una concepción del derecho fundada en la importancia del factor histórico y la consecuente revalorización del sentido cristiano atribuido a la ley, en conformidad con el orden moral.

El recurso a la eficacia técnica como pieza clave del engranaje administrativo perpetuaría la autoridad competencial del Ejecutivo, dentro de una correlación legal con el resto de organismos sociales de la nación, que sintetizaría el interés particular y general en el marco del Estado jurídico ${ }^{53}$.

El interés de muchos administrativas españoles por emancipar el Derecho de las doctrinas extranjeras de corte liberal, contribuyó a una profusión de estudios históricos que pretendían compilar las disposiciones legales propias con el fin de reformar el entramado jurídico. En este sentido, la influencia del Estado Novo se dejó sentir en España poco después de la Guerra Civil cuando algunas universidades organizaron misiones culturales para la formación de juristas en

${ }^{50}$ Véase Marcelo Caetano, Tratado elemental de Derecho Administrativo, Santiago de Compostela, Galí, 1946.

${ }^{51}$ Véase Sergio Campos Matos, "Da crise da Monarquia constitucional à Primeira República em Portugal (1890-1910)", en Hipólito de la Torre (coord.), España-Portugal..., cit., p. 58.

52 "Toda la vida administrativa debe estar dominada por dos principios fundamentales: la concentración y la continuidad, que exigen la estabilidad y la independencia del Gobierno. La concentración requiere la reunión de todos los elementos materiales de los que haya necesidad para resolver un problema determinado y también la sumisión a una dirección única de todos los elementos humanos que deben colaborar en este trabajo. [...] Pero la concentración y la continuidad de la vida administrativa son imposibles, afirma Salazar, si el Poder ejecutivo no es estable e independiente." Francisco Ignacio Pereira dos Santos, Un Estado corporativo. La Constitución social y política portuguesa, Madrid, Ed. Reus, 1945, p. 186-187.

53 "Como soberano, el Estado se constituye y legisla, pero al administrar, el mismo Estado sólo tiene aquel poder que sus propias leyes le confieren, un poder que es autoridad pero no soberanía, aunque derive de ésta. Así la legalidad, o sumisión de la administración a las leyes, es condición esencial para la existencia del Derecho administrativo." Caetano, Tratado..., cit., p. 51 . 
Portugal. Si bien es verdad que la evolución de los países peninsulares estuvo condicionada por sus propias circunstancias, lo cierto es que coincidirían en la idea de desentrañar del Derecho natural las normas positivas por las que debían regirse las actividades humanas. Esta confluencia del pensamiento católico-tradicionalista y la técnica de la ciencia jurídica anglosajona, determinaría la organización de sus respectivas administraciones ${ }^{54}$.

En buena medida, la organización de las directrices administrativas para el impulso del desarrollo económico en España, también se inspiraría en los patrones portugueses. La integración del Estado Novo en las estructuras de la economía internacional definidas a partir de 1945, facilitó la adhesión del régimen portugués a las tesis del desarrollismo como palanca de crecimiento y antídoto contra la agitación social, sumándose al proceso generalizado de la programación indicativa. Desde los inicios de los años cincuenta la actividad de los mecanismos planificadores del salazarismo constituyeron un referente para la estructuración en España de la futura Comisaría del Plan. En efecto, la Oficina de Coordinación y Programación Económica (OCYPE) se preocupó por recabar información acerca de aquellos organismos de su entorno que mejor respondían a un modelo centralizado en la Presidencia del Gobierno.

El interés por el modelo luso residía en la creación de un conducto especializado en el seno del Gobierno, que tomaba a su cargo los problemas relacionados con la elaboración de sus Planes mediante la Inspección Superior del Plan de Fomento, integrado en la Secretaría General de la Presidencia del Consejo. Se coordinaban así los elementos requeridos por las entidades públicas y privadas, ligadas a la Comisaría Interministerial del Plan de Fomento para estudiar el programa de inversiones, cuyo procedimiento de aplicación suscitaría el interés de las autoridades españolas para valorar su posible adopción, llegado el caso ${ }^{55}$. La Inspección Superior constituía, por tanto, un servicio de

${ }^{54}$ Las breves reflexiones de Laureano López Rodó en una carta a Marcelo Caetano en la que aprecia positivamente la metodología utilizada en una de sus obras, con el recurso al análisis histórico, unido al acierto con que califica las observaciones del Catedrático portugués acerca de la reacción de la vida social sobre la ley, perfilan una solidaridad de criterios arraigada en una misma concepción del derecho. Carta de Laureano López Rodó a Marcelo Caetano (08/06/1948). AGUN/LLR.

55 "En esta Presidencia del Gobierno se están realizando estudios económicos relativos a las inversiones públicas y privadas. Con tal motivo, nos gustaría saber si, en su país, los planes de inversiones son promulgados mediante disposición legal y, en caso afirmativo, nos sería de gran utilidad el disponer de un ejemplar o copia de dichas leyes o disposiciones. Ruego, por tanto, a usted tenga la bondad de suministrarme la información anterior por lo que, de antemano, le expreso mi sincero reconocimiento." Carta de Laureano López Rodó a Marcelo Caetano $(02 / 12 / 1957)$. AGUN/LLR. 
estudio y coordinación sin responsabilidades de administración, cuyo personal burocrático estaba conformado por los funcionarios de la Secretaría General de la Presidencia que, para el caso, eran seleccionados por medio de un concurso de pruebas documentales y prácticas en los términos marcados por la ley ${ }^{56}$.

El esquema del Plan de Fomento en Portugal respondía a la influencia organizativa del modelo francés, promotor de la planificación indicativa en Europa, a pesar de la propia peculiaridad lusa en el encuadre de su actividad económica ${ }^{57}$.

Las diferencias procedimentales de los órganos de planificación en la Península vendrían marcadas por la adopción de un modelo administrativo de gestión directa en el caso español, frente a la función coordinadora del organigrama portugués. En cualquier caso, la centralidad de los mecanismos decisorios en torno a la Presidencia asegurarían la unión de esfuerzos en el proceso de vigorización industrial ${ }^{58}$ y demostraba que, una vez más, la influencia del salazarismo en España se remontaba a la funcionalidad de una incipiente administración, inserta en las estructuras políticas de un Estado autoritario, que inspiraría la articulación del régimen franquista ${ }^{59}$.

No obstante, la inversión de etapas políticas en el ámbito peninsular por las cuales a partir de 1958 Portugal cerraría su ciclo reformista, mientras que España lo iniciaría con su apuesta por la liberalización económica, terminaría provocando un paulatino cambio de influencias. Sobre todo entre la corriente aperturista portuguesa, que minaría las transformaciones acaecidas en España como un modelo a seguir para actualizar las anquilosadas estructuras del Estado Novo, una vez operada la revisión constitucional de 1958 al restringir el proceso de elección presidencial a un colegio de notables. Las reformas impulsadas por los equipos técnicos del gobierno español a partir de 1957, en especial desde los departamentos de Hacienda y Comercio, protagonistas del Plan de Estabilización de 1959, que sentaría las bases para inaugurar una década de cambios que acelerarían la modernización del país, adelantándose a Portugal en índices de crecimiento económico y mejora de los niveles de vida ${ }^{60}$, confirmarían el interés de sus homólogos portugueses por adoptar ese modelo renovador llamado a perpetuar por esos cauces la continuidad del sistema:

${ }^{56}$ Archivo General de la Administración (AGA), Presidencia, Comisaría del Plan, caja 4496.

${ }^{57}$ Fernando Rosas, Salazarismo..., cit., p. 33.

${ }_{58}$ Archivo de la Presidencia del Gobierno (APG), Subsecretaría orgánica, leg 184, caja 4796.

${ }^{59}$ Javier Tusell, La dictadura de Franco, Madrid, Alianza, 1988, p. 282.

${ }^{60}$ Pablo Martín Aceña, Elena Martínez Ruiz, "La edad de oro del capitalismo español: crecimiento económico sin libertades políticas", Nigel Townson (Ed.), España en cambio: el segundo franquismo, 1959-1975, Madrid, Siglo XXI, 2009, p. 12. 
Aliás, a política española interessa-me profundamente, neste momento sobretudo em que vejo posta em practica, como notable êxito, a política de descentraçâo e flexibilizaçâo do regime, por mim preconizada para Portugal em 1955 e que aquí nâo logrei fazer vingar em desgosto meu e prejuizo geral ${ }^{61}$.

Además de la apuesta de los responsables ministeriales por impulsar el dinamismo de la actividad turística e industrial, dentro del marco de la programación económica indicativa que atrajo un mayor índice de inversiones extranjeras, se procedió a una paralela apertura política. La promulgación de la Ley de Prensa e Imprenta en 1966 bajo el patrocinio del Ministro de Información y Turismo, Manuel Fraga, por la cual se eliminaba la censura previa, a la vez que se contemplaba el secuestro editorial como mecanismo de control en caso de trasgresión de los Principios Fundamentales del régimen o de injuria a las instituciones, coincidió con la puesta a punto de la mentada Ley Orgánica del Estado. Esta séptima ley fundamental, sometida a referéndum en diciembre de 1966, ordenaría los principales poderes del Estado con la consiguiente revisión de varios artículos de la legislación anterior relativas a esta materia. Entre sus novedades destacaría una delimitación más reglada de las atribuciones del Jefe del Estado, sobre todo una vez que se cumplieran las previsiones sucesorias, todavía por determinar, dado que el nuevo Rey o Regente no podría heredar las facultades contempladas en la Leyes de 30 de enero de 1938 y 8 de agosto de 1939, a las que ya nos hemos referido.

La norma también introducía el procedimiento para nombrar al Presidente del Gobierno a través del Consejo del Reino, cuyos miembros someterían a deliberación varias candidaturas, con la elaboración de una terna de presidenciables presentada al Jefe del Estado, de entre los cuales nombraría al responsable del Ejecutivo. De este modo, se contemplaba la desvinculación de jefaturas asumidas por Franco desde la guerra, por medio de un mecanismo que salvaba el carácter corporativo del sistema. Un presupuesto también aplicado a las Cortes, por cuanto introducía el llamado tercio familiar de representación, por el cual serían elegidos dos procuradores por cada provincia de entre aquellas candidaturas que reunieran los avales previstos por la ley, mediante el sufragio de las personas casadas y de las solteras ya emancipadas. La inclusión de estos representantes de elección directa, unido a la posibilidad de que se formaran

\footnotetext{
${ }^{61}$ Carta de Marcelo Caetano a Laureano López Rodó (22/01/1963). AGUN/LLR.
} 
entidades territoriales distintas a las de la provincia, entreabriendo un hipotético reconocimiento jurídico a las regiones en lo que pudiera tener de descentralización, significó un avance en relación con la etapa anterior. La proclamación del Príncipe Juan Carlos de Borbón como sucesor a la Jefatura del Estado a título de Rey por el Pleno de las Cortes Españolas convocado el 22 de julio de 1969, cerraría la senda de la institucionalización y convertiría al régimen en un referente para otros países de similar inspiración ideológica.

En este sentido, la reforma emprendida en Portugal por Marcelo Caetano al asumir la Presidencia del Consejo en 1968 fue alentada por algunos aperturistas españoles ${ }^{62}$. A pesar de que la modificación de algunos artículos de la Carta Magna portuguesa en 1971 destinados a la actualización del sistema llegó con retraso, fruto del inmovilismo predominante en los últimos años del salazarismo. Su objetivo fue salvar el estancamiento de la economía e intentar dar solución a los graves problemas de Ultramar que evitaran la erosión del régimen. La predisposición del Gobierno portugués de incrementar los intercambios comerciales con España para mejorar la cooperación económica a dos bandas, dentro de la progresiva creación de un mercado común peninsular, partía de una idea esbozada ya a finales de los años cincuenta y reactivada por el Gabinete portugués de 1970, con el cuidado de la gestión administrativa y un nuevo impulso al desarrollo económico ${ }^{63}$.

La remisión de varios ejemplares del III Plan de Desarrollo Económico y Social aprobado por las Cortes Españolas para el cuatrienio 1971-1975 al Presidente del Consejo portugués y a sus Ministros del área económica, fue una de las iniciativas del responsable español de la Comisaría del Plan. Desde 1963 López Rodó había asumido ese cometido, que en su tercera edición postulaba el acercamiento de los niveles de renta en el ámbito personal y geográfico ${ }^{64}$.

62 "Yo quería, ante todo, felicitarle a usted por el notorio éxito político que representa la aprobación de la nueva Constitución portuguesa. Revela, una vez más, sus grandes dotes de jurista y su talento y prudencia de hombre de Estado. He leído detenidamente los 143 artículos del título constitucional que se caracterizan, a mi juicio, por su ponderación y su justo equilibrio entre los caracteres esenciales de la Nación portuguesa y las exigencias de cada nueva circunstancia histórica. He leído con particular interés el título relativo a Ultramar, que constituye un verdadero acierto.” Carta de Laureano López Rodó a Marcelo Caetano (19/07/1971). AGUN/LLR.

${ }^{63}$ Eurico Carlos Esteves Lage Cardoso, Segunda República (1926-1974), Ediçâo do Autor, Lisboa, 2010, p. 196-197.

${ }^{64}$ Laureano López Rodó, Memorias. El principio del fin, tomo III, Barcelona, Plaza y Janés, 1992 , p. 216. 
Motivo por el que consideró oportuno establecer contacto con las autoridades portuguesas, con el fin de acercar posiciones sobre la materia, dados los condicionantes económicos y las aspiraciones españolas de ingresar en la EFTA como trampolín para la creación de un espacio hispano-luso de libre cambio ${ }^{65}$ :

Comparto plenamente su desencanto por lo poco que se ha avanzado en la cooperación económica peninsular. Me entristece ver que, pese a una mayor diferencia entre los niveles de renta respectivos, la cooperación con Francia y con Alemania se acrecienta de día en día, mientras que con Portugal [...] se encuentran casi en vía muerta. Sigo pensando que sólo con una decisión al más alto nivel que permita establecer un marco institucional de cooperación económica -una zona de libre cambio como primer paso hacia un mercado común peninsularse obtendrían resultados efectivos y satisfactorios para ambos países ${ }^{66}$.

En el fondo de esta propuesta de carácter técnico, subyacía la idea de reforzar las economías ibéricas en una suerte de alianza peninsular más compenetrada, para llevar a término la misión civilizadora con arreglo a unos principios informados por la percepción católica y tradicional del mundo ${ }^{67}$. Toda una línea de pensamiento corroborada por las declaraciones del Presidente de la República portuguesa en su visita a la embajada de España en Lisboa en 1962, al subrayar el ejemplo único de resistencia que representaban ambas naciones ante los llamados vientos de la Historia ${ }^{68}$. El intento por erigir unos regímenes políticos alternativos a las corrientes filosóficas de la modernidad, apoyados en un sistema de ideas acorde con las tesis del culturalismo tradicionalista, sería lo que vendrían a representar los autoritarismos ibéricos hasta los años setenta.

${ }^{65}$ El propio Caetano había mostrado sus preferencias por una adhesión de España a la EFTA, aunque en modo alguno la condicionaba para sellar acuerdos bilaterales en la constitución de una zona peninsular de libre cambio. Sin embargo, consideraba que aquella Asociación representaba una mayor garantía jurídica para el cumplimiento de los acuerdos suscritos, además de eliminar resistencias internas que pudieran sobrevenir. Véase la Carta de Marcelo Caetano a Laureano López Rodó (24/08/1972). AGUN/LLR.

${ }^{66}$ Carta de Laureano López Rodó a Marcelo Caetano (25/11/1971). AGUN/LLR.

${ }^{67}$ Pedro Carlos González Cuevas, Acción Española. Teología política y nacionalismo autoritario en España 1913-1936, Madrid, Tecnos, 1998, p. 93-94.

${ }^{68}$ Diario de Sevilla, 28 de febrero de 1962. 


\section{Conclusiones}

La influencia del Estado Novo en el proceso de configuración del franquismo viene determinado por su común procedencia ideológica. En efecto, la fundación del primer Estado corporativo del mundo manifestó la posibilidad real de articular un modelo político superador de las corrientes liberales y marxistas en la organización del Estado.

$\mathrm{Al}$ igual que otros regímenes del período de entreguerras, el caso portugués se inscribe en un esquema inicial basado en la herencia del regeneracionismo autoritario. Sin embargo, la confluencia de corrientes ideológicas en el seno del sistema acabaría inclinándolo hacia las posiciones sostenidas por el tradicionalismo ideológico. Cierto es que el fenómeno se enmarca en un contexto caracterizado por la crisis de la cultura contemporánea, en el que la construcción de una alternativa capaz de superar el legado filosófico de la modernidad se convertiría en el hito del pensamiento católico-tradicional.La aplicación práctica de ese ideario en el régimen de Salazar constituiría un referente para otros países católicos, después del fracaso de la experiencia austriaca del canciller Dollfuss.

La aportación ideológica del salazarismo entre los grupos de la derecha confesional en España durante la Segunda República, no era más que una coincidencia de planteamientos surgidos de la misma escuela de pensamiento. En realidad, la continuidad de aquellas tesis se verían reforzadas por sucesivos ejemplos prácticos que alcanzarían su punto álgido con la institucionalización completa del Estado Novo que, aún así, incorporó no pocos aspectos organizativos de la dictadura de Primo de Rivera. Estos modelos, que irían complementándose en su mutua cosmovisión tradicionalista, les llevaría a una creciente cooperación en el plano internacional, para proceder con mayor eficacia en la defensa de la civilización cristiana.

Esta unicidad de pensamiento implicaba, cuando menos, una seria reserva frente a la manifestación del pluralismo político, condicionado por la rigidez de los cauces de participación. Sin embargo, la mayor flexibilidad del salazarismo en la expresión ordenada de criterios políticos era el resultado de un eclecticismo constitucional que inspiró a los grupos tradicionalistas españoles frente al rigorismo de la estructura de FET y de las JONS. Aunque la posibilidad de contemplar una oposición articulada e integradora en los parámetros legales del franquismo no llegó a cuajar, lo cierto es que se intentaría adoptar el modelo portugués en lo referente a la diversidad orgánica del Movimiento, como contrapeso del poder falangista.

Esta diferencia sustancial de los regímenes peninsulares radicaba en su propio origen. En el caso portugués, no se planteó una ruptura drástica con 
el pasado inmediato hasta la paulatina aplicación de la Constitución de 1933, conservando el propósito de integrar a buena parte de grupos y sectores políticos en los parámetros legales del nuevo Estado. De ahí la articulación de una oposición organizada para los períodos electorales. Por su parte, la génesis del franquismo estuvo marcada por una guerra civil que rompió con todo lo que representaba la República, dificultando un proceso de integración.

Los apuntes sobre la reforma administrativa y la organización de los mecanismos de planificación económica, constituyeron referentes precisos para una España que todavía no había concluido su proceso de institucionalización. La ejecución de aquellas reformas por parte de los sectores franquistas, vinculados al Ministerio de la Presidencia, facilitó un acercamiento al Estado Novo, en tanto que siempre había constituido una de sus primeras fuentes de inspiración para su articulación política. 